\title{
Building Climate-based Daylighting Models Based On One-time Field Measurements
}

\author{
Geraldine Quek $^{1}$, J. Alstan Jakubiec ${ }^{2}$ \\ ${ }^{1}$ Laboratory of Integrated Performance in Design (LIPID) \\ École Polytechnique Fédérale de Lausanne \\ 2 John H. Daniels Faculty of Architecture, Landscape and Design \\ School of the Environment University of Toronto
}

\begin{abstract}
Calibrated climate-based lighting simulation models of buildings perform an essential role in postoccupancy evaluations (POE), such as annual frequency assessments of daylighting quality and visual discomfort. However, the role of lighting analysis is temporally limited by instantaneous measurements or limited in scale by requiring constant monitoring of occupied spaces with expensive sensors. Building calibrated models is thus challenging due to limited information, short durations of access, the concurrent presence of electric lighting and daylighting, and transient usage of dynamic shades of occupied spaces. In this paper, the authors present a calibration process to build annual daylighting and electric lighting simulation models based on one-time field measurements, exemplified through a dataset of 540 individual office desks across 10 office spaces. The authors calibrated lighting models to be reliable enough for assessing the relationship of annualized climate-based daylighting metrics (CBDMs) to participants long-term perceptions of lighting quality. The proposed process to build calibrated climate-based models for POE's based on one-time field measurements at each building is validated through comparing measured and simulated illuminance data at every work desk and results are sufficiently positive with logarithmic relative RMSE values of $4.3 \%$ and $6.8 \%$ and relative RMSE values of $25.8 \%$ and $45.5 \%$ for horizontal and vertical illuminances respectively. Vertical illuminance was found to vary more with measured data due to the uncertainty of monitor screen luminances. This paper demonstrates that measured data through onetime visits can be utilized to build reliable calibrated lighting simulation models to integrate long-term annual lighting results in post-occupancy evaluations.
\end{abstract}

\section{Introduction}

Simulating daylighting and electric lighting in digital architecture models in various stages of design have become quintessential for informing design decisions to meet quantitative and qualitative lighting goals by predicting building performance prior to construc- tion. Post-occupancy evaluations (POE's) of completed buildings and spaces close the loop by providing feedback on the end-quality of a design to the building and construction industry who can assess if the project brief was met as well as serve an important role by allowing researchers to generate knowledge of occupant well-being based on actual user experiences.(Oseland (2007)) Most POE's focus on instantaneous measures of illuminance or visual comfort using High Dynamic Range (HDR) photography techniques within a monitoring time period. However, architects, energy consultants, engineers, lighting designers and researchers designing for daylight today use computer daylighting simulations and annualized lighting measures (Reinhart and Fitz (2006)) and recently including climate-based daylighting metrics (CBDMs) and annual visual comfort analysis to assess potential designs instead of static daylighting metrics (Reinhart et al. (2006)). To truly 'close the loop', these annual daylighting metrics need to be evaluated based on a comparison with overall user perceptions of space and the annual lighting they experience. To this end, this manuscript describes a process of calibrating daylight simulation models during POE field studies which can be used to calculate annual CBDMs as a component of building POE's based on short-term visits instead of long-term monitoring. Having said that, the proposed methodology does not aim to replace current POE methods but rather to extend and refine the capabilities of POE's by correlating actual annual daylighting metrics to the overall queried experiences of occupants.

\section{Background}

Many measurement-driven POE studies in the research literature are based on instantaneous measurements and do not utilize long-term monitoring nor annual predictive data. Bear and Bell (1992) measured illuminance, source luminances, surface reflectance, geometric factors and subjective information for 471 participants as early as 1992. Parpairi et al. (2002) measured luminance and illuminance values manually at offices and libraries. Dahlan et al. (2009) measured discomfort glare metrics using High 
Dynamic Range (HDR) photography along with illuminance and subjective information. Choi et al. (2012) measured instantaneous luminance using HDR photography and illuminance using a mobile sensor cart. Hirning et al. (2013, 2014, 2017) measured discomfort glare using HDR photography where photographs were taken from the occupant's point of view where participants filled out a short subjective survey. Mangkuto et al. (2017) used HDR photography to measure luminance and glare metrics in a library space with measures paired with subjective information. In summary, for direct measurement POE studies, it is feasible to quickly collect a large number of data from a diverse range of participants. However, limitations do emerge - the vast majority of studies collect limited seasonal or temporal data, localizing the results at the specific point-in-time the measurements are taken.

Another approach employed by researchers has been to utilize long-term data monitoring in order to gather a more holistic representation of POE participant's lighting experiences. Fan et al. (2009) recorded HDR photographs and frequent subjective information using a computer application for 5 occupant workstations. Cameras were mounted as close to the head position of the occupant as feasible, which resulted in errors generally below $25 \%$. Konis (2013, 2014) recorded ambient environmental conditions, HDR photographs, and subjective ratings on a continuous scale. Drosou et al. (2016) installed 2 high-quality HDR camera capture setups in classrooms, monitoring their lighting performance every 10-minutes for an entire year. Limitations included a period of data loss due to camera shutter failure and a single, fixed viewing location not from an occupant point of view. Extrapolating from the above studies, continuous measurement studies are limited by the cost and maintenance of equipment, thereby enhancing the quality of data per participant but limiting the number of participants for which data can be reasonably and affordably collected over a period of time.

A third, but less utilized, approach is to employ daylighting simulations, often using a validated Radiance-based engine such as DaysimWard (1994); Reinhart and Walkenhorst (2001). Reinhart et al. (2014) used quasi-calibrated CBDM results paired with subjective data to identify annual lighting performance levels that correlate with perceptions of 'daylit.' Jakubiec and Reinhart (2016)used a daylighting model based on measured material properties, exacting geometric reconstructions, and specific weather data to assess annual lighting and glare metrics at a 6-minute time interval, but the model's calibration was not checked with measurements, and contributions from electric lighting were ignored. Bellia et al. (2017) expressed the opinion that this approach was not feasible due to the complexity and time com- mitments of modeling data. Mardaljevic et al. (2016) noted that CBDMs are difficult to validate in practice due to obstructions on the workplane where sensors would ordinarily be placed for long-term monitoring and that illuminance data is not ordinarily a part of building management systems. They propose to use a continuous luminance camera to derive illuminance on vertical surfaces in order to validate CBDM illuminance calculations. Other researchers have noted the importance of appropriate material properties in simulations to achieve accurate results. (Jakubiec (2016); Brembilla et al. (2015))

\section{Methodology}

In this section, the authors seek to showcase the workflow to obtain annual climate-based daylighting models from one-time measurements at any building and location. Measurements at office desks of 540 occupants in 10 offices were recorded during the period between October 2016 and August 2017. Calibrated climate-based daylighting models were then built according to field measurements: HDR images, illuminance and luminance measurements, material reflectance measures, space measurements, and external weather data. Figure 1 explains the general overall workflow. Computational scripts were written to automate each process due to a large amount of data.

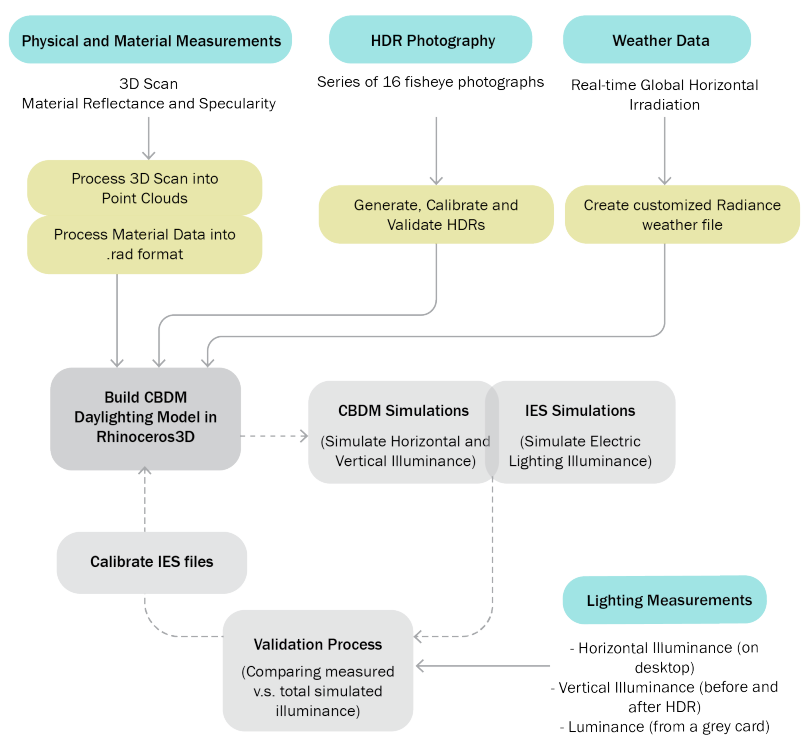

Figure 1: Overall workflow for calibrating climatebased daylighting models from single point-in-time measurements.

\section{Field Measurements}

Of the 10 offices measured, some occupy multiple floors, and 2 offices are situated in the same building separated by 12 floors. Beyond formal and layout differences, each office has different material finishes and luminaire selection. High Dynamic Range (HDR) photographs, workplane, and vertical illuminance, and luminance measurements from a neutral 


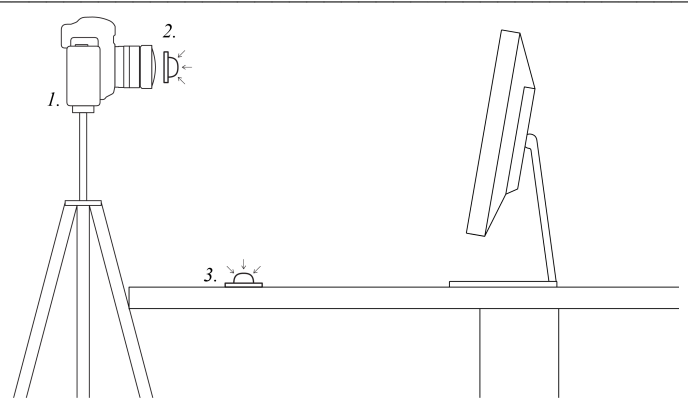

(a) 1. Camera setup for HDR photography, 2. Vertical illuminance measurement location, 3. Horizontal illuminance measurement location.

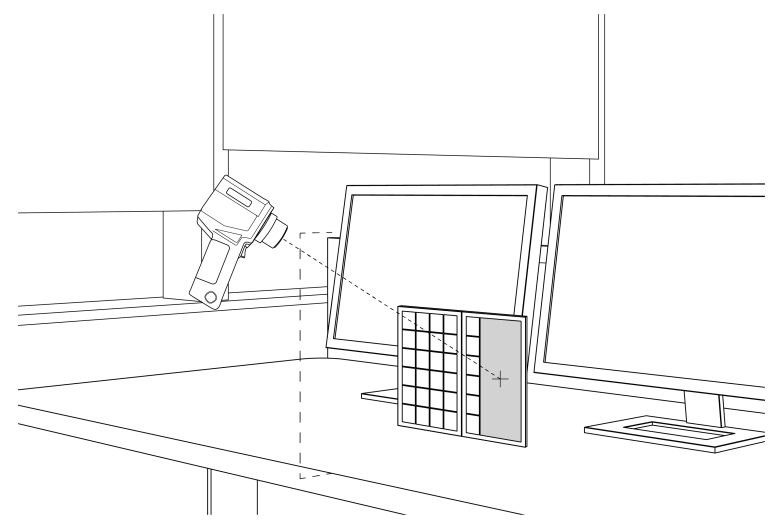

(b) Luminance measurement setup.

Figure 2: Measurements and HDR photography setup.

grey card were captured and recorded at each of the 540 occupants' desks. Occupants were asked immediately preceding the measurements to fill out a short 5 -minute subjective survey on their perceptions of instantaneous and long-term lighting quality. Before measurements are taken, occupants are asked to leave their desk such that the camera and lighting sensors can be positioned freely at the eye position and on the workplane. Horizontal illuminance $(l u x)$ on the desktop surface is measured once after the HDR photographs are taken. Figure 2 illustrates the positioning of the illuminance and luminance meters for the respective measurements. Luminance measurements $\left(\mathrm{cd} / \mathrm{m}^{2}\right)$ from a grey card are recorded with a luminance meter (Konica Minolta LS-100), and vertical illuminance (lux) is recorded with an illuminance meter (Konica Minolta Illuminance Meter T-10A or Illuminance Spectrophotometer CL-500A) before the first exposure and after the last exposure of the HDR photographs are captured, in front of the fisheye lens from the occupant's viewpoint. The average value of the before and after luminance measurements are used in calibrating the images, to account for minor changes in lighting levels during the HDR capture. If illuminance or luminance values differ significantly, the image is discarded.

\section{HDR Photography}

HDR fisheye photographs were taken at each occupant's desk to capture luminance values from their point of view shortly after filling out the subjective survey, see Figure 3. The methods used are according to the recommendations proposed by Inanici (2006); Jakubiec et al. (2016). The occupant is asked to vacate their desk before the measurements start- see Figure 2a. A full frame DSLR camera (Canon EOS 5D Mark III) with a fish-eye lens (Canon EF 8-15mm f/4L Fisheye USM or Sigma 8mm f/3.5 EX DG Circular Fisheye Lens) was used with a stable tripod. A series of 16 photographs with exposure times at an interval of 1 stop from $8 \mathrm{sec}$. to 1/4000 sec. were taken. The individual exposures were converted to the Radiance angular fisheye (-vta) image projection (Ward (1994)) based on measurements of the lens projections taken with a panoramic tripod head. The images are then cropped to a 180-degree opening angle with a circular mask and resized to 800 x800 pixels. The series of photographs were then converted into HDR images using Photosphere (Ward (2005)). Approximately half of the HDR images captured in this study did not have a corresponding luminance measurement. These images were calibrated based on vertical illuminance measurements taken at the camera lens. Images with a corresponding luminance measurement were then calibrated in Photosphere manually using the luminance data measured on the grey card. Finally, vignetting correction was applied to the HDR photos to correct for light attenuation at the edge of the fisheye photograph(Jakubiec et al. (2016)).
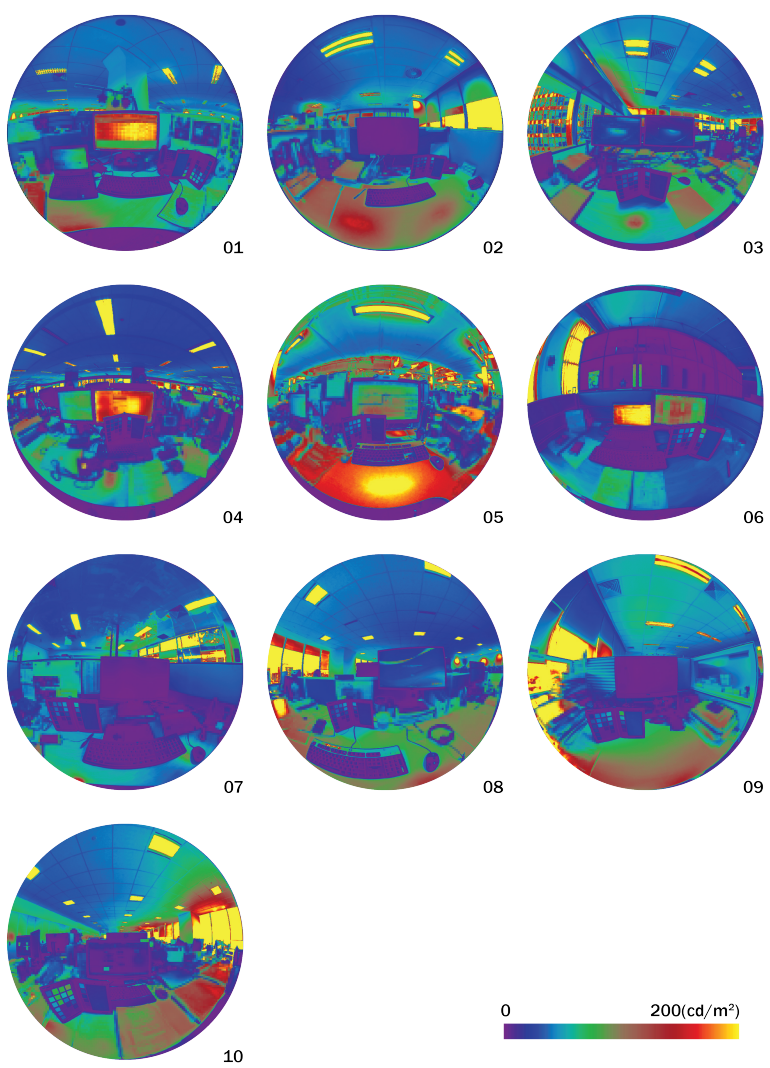

$200\left(\mathrm{~cd} / \mathrm{m}^{2}\right)$

Figure 3: An example of HDR image collected from each of the 10 office spaces measured. 


\section{Physical Measurements}

A laser scanner (FARO FOCUS 3D X330) was used to scan the interiors and exteriors of the office spaces that act as a geometric reference for the precise construction of a 3D model by approximating the interior layout including dimensions and positions of furniture and electric lighting, see Figure 4. The scan files were processed into point clouds and finally used to build a detailed surface model in Rhinoceros 3D (McNeel and Associates (2017)). However, laser scanning is an optional step and may be replaced by hand measurements, or using as-built BIM-models after verifying their measurements. The surface geometry created in this step is converted to polygonal meshes and exported to the Radiance .rad format (Ward (1994)).
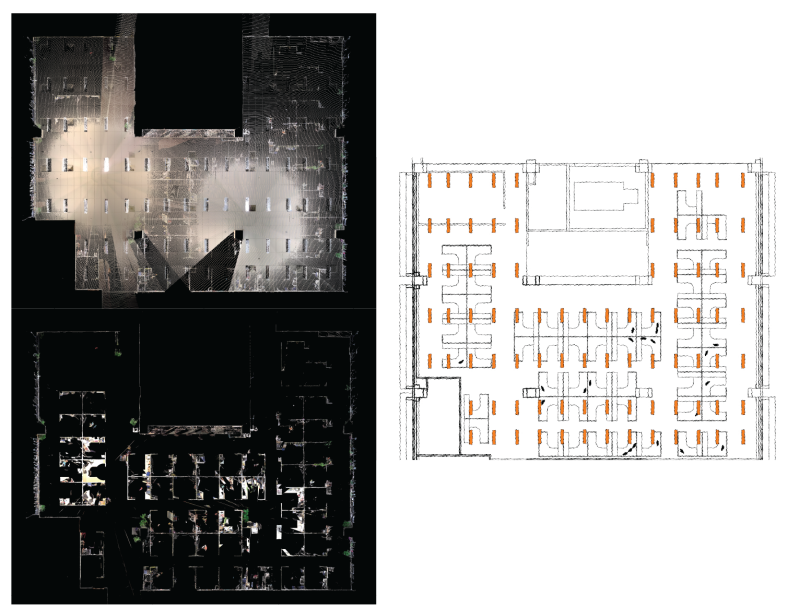

Figure 4: Example of 3D scan point cloud and screen captures of furniture plan and luminaires (orange rectangles).

Measurement of Material Reflectance Data \& Translation to Radiance Material Definitions

Material reflectance data of surfaces were measured using a spectrophotometer (Konica Minolta CM2600d Spectrophotometer) based on an average value of three-point measurements across each surface material type. Each material finish had two types of reflectance recorded, Specular Component Included (SCI) and Specular Component Excluded (SCE) respectively which are both full-spectrum colorimetric measurements. The material data was converted to Radiance material definitions as described by Jakubiec (2016). Where the glazing transmittance information is not obtainable, it was either measured if the windows are operable or estimated from initial visualization simulations. Where the glazing transmittance was known, it was converted to transmissivity by multiplying by 1.09 (Jacobs (2012)). A generic monitor model was used for all the desks, modeled according to Jones and Reinhart (2017) but with modifications to match the average observed screen luminances in Singapore with a high-state pixel luminance of 125 $\mathrm{cd} / \mathrm{m}^{2}$ and low-state pixel luminance of $33 \mathrm{~cd} / \mathrm{m}^{2}$.
A generic roller blind with a direct normal transmittance of 0.01 , front reflectance of 0.37 , back reflectance of 0.56 and diffuse transmittance of 0.2 , and transmittance that drops to zero at 84 degrees, was used.

\section{External Measurements}

Global horizontal solar irradiation $\left(\mathrm{W} / \mathrm{m}^{2}\right)$ is measured in real-time from an existing weather station located at the rooftop of the authors' university campus at $36 \mathrm{~m}$ above ground level with no urban obstruction, using a silicon pyranometer and recorded every 5 minutes by a data logger. Global horizontal solar irradiation was split using the Reindl et al. (1990) method into direct-horizontal and diffuse-horizontal irradiance. A customized Radiance .wea weather file (Reinhart and Walkenhorst (2001)) was then created for each office space back-dated one year from the date of visit.

\section{Validation of HDR Images}

To validate the accuracy of the HDR images, which will be used for glare analysis and point-in-time calibration of the daylighting model, measured vertical illuminance, $E_{m e a}$, was compared to the total pixel illuminance contribution from the equiangular HDR images $E_{v}$, as calculated in equation 1 . As the HDR images with illuminance measurements were calibrated to the measured illuminances, only the HDR images that were calibrated through the luminance measurements are included in this validation. The grey line illustrates the ideal calibration of HDR images, and it is notable that the total pixel illuminance contribution fell slightly below than the sensor measured vertical illuminance for luminancecalibrated images.

$$
E_{v}=\sum_{\theta_{p}<90^{\circ}} L_{p} \omega_{p} \cos \theta_{p}
$$

where $L_{p}$ is the luminance $\left(\mathrm{cd} / \mathrm{m}^{2}\right)$ of the individual pixel, p, $\omega_{P}$ is the solid angle $(s t r)$ of that pixel, and $\theta_{p}$ is the incident angle from the pixel to the center of the photograph. The authors then calculate the root mean squared error (RMSE) between the HDR illuminance and sensor-measured illuminance with equation 2 as follows:

$$
R M S E=\sqrt{\frac{\sum\left(E_{v}-E_{m e a}\right)^{2}}{n}}
$$

where $E_{v}$ is the total pixel illumination contribution derived from $n$ number of HDR images, $E_{\text {mea }}$ is the measured vertical illuminance. The relative RMSE, $R M S E_{r e l}$, refers to the percentage deviation from the mean while relative mean bias error $M B E_{r e l}$ is the Mean Bias Error relative to the mean. Both were 
calculated according to Equations 3 to 5:

$$
\begin{gathered}
R M S E_{r e l}=\frac{R M S E}{\bar{E}_{m e a}} \\
M B E=\frac{\sum\left(E_{v}-E_{m e a}\right)}{n} \\
M B E_{r e l}=\frac{M B E}{\bar{E}_{\text {mea }}}
\end{gathered}
$$

where $\bar{E}_{m e a}$ is the mean of the measured vertical illuminances. RMSE on the logarithmic scale is also calculated, as the photopic sensitivity response of the human eye to lighting intensity is on a logarithmic scale rather than on a linear basis. (Reinhart and Andersen (2006)) Hence $\log R M S E_{\text {rel }}$ is also calculated as per Equations 6 to 7 :

$$
\begin{gathered}
\log R M S E=\sqrt{\frac{\sum\left(\log _{10} E_{v}-\log _{10} E_{m e a}\right)^{2}}{n}} \\
\log R M S E_{r e l}=\frac{\log R M S E}{\log _{10} \bar{E}_{\text {mea }}}
\end{gathered}
$$

The results showed a $R M S E_{\text {rel }}$ of $23.24 \%$ in linear space, $\log R M S E_{\text {rel }}$ of $9.60 \%$ in logarithmic visual space, a slight negative bias of $-9.91 \% M B E_{r e l}$, where $M B E$ in linear space is -21.9lux.

\section{Calibration of Electric Lighting}

As the exact model and lamp selection of the luminaires were not available, an appropriate IES file (Committee et al. (1991)) was selected to be used in the simulation models, based on luminaire dimensions and photometric distributions observed in the captured HDR images. After loading the IES file into the lighting simulation model, the luminaires were located as per the 3D scan data. An occupant's viewpoint was simulated using high-quality ambient Radiance parameters, and the global horizontal irradiance value that is recorded by the weather station nearest to the time of field measurement was used as the input for the Perez all-weather sky model (Perez et al. (1993)) during a calculation. To keep daylight contribution to a minimum, a viewpoint further away from the facade was chosen when calibrating the photometric distribution and intensity of electric lighting data. A scale factor is approximated and ies2rad was run to multiply the brightness output of the luminaires. This process was repeated until an appropriate scaling factor was reached.

\section{CBDM Simulation Data and IES Simulation Data}

Grid-based annual lighting simulations without roller blinds and electric lighting were run for all 10 office spaces indicating the various daylighting conditions due to the diverse building typologies, mate- rials, floor plans, and building depths. Figure 5 illustrates the variation of daylight experienced by the participants in the 10 surveyed office spaces represented by Annual Mean Illuminance. A red line illustrates a Daylight Autonomy value of [75\%] at an illuminance threshold of 300 lux. For validation purposes, climate-based daylighting simulations were ran using Daysim (Reinhart and Walkenhorst (2001)) for each office space, with roller blinds, per 5-minute time step using the custom weather data file generated for each office space. Since light is additive, the simulated daylight and electric light illuminances were simulated separately and are summed up to calculate total simulated horizontal or vertical illuminance.
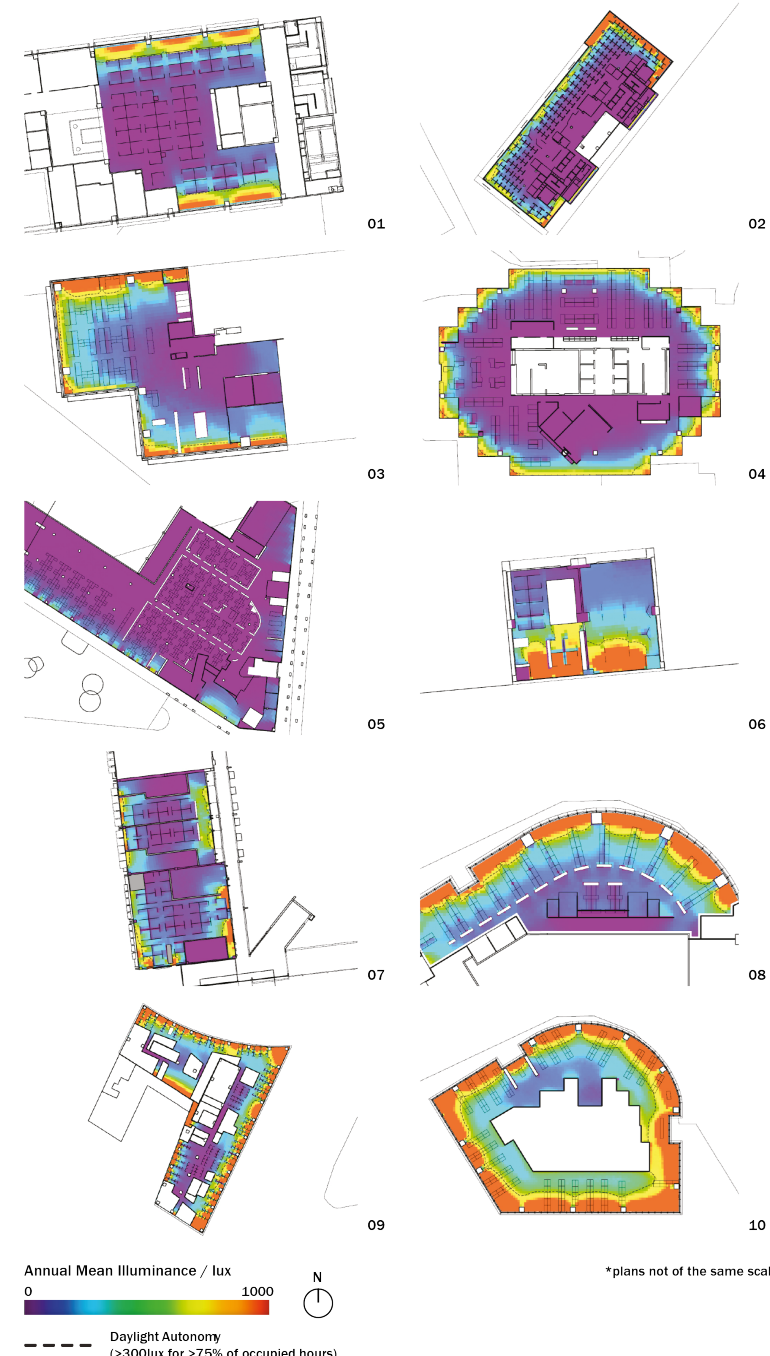

- - - - Dayight Autonong

Figure 5: Annual Mean Illuminance and Daylight Autonomy for all 10 offices simulated (without roller blinds and electric lighting).

\section{Results}

After the iterative process of calibrating the electric and daylighting portions of the lighting simulation models (see Figure 1), the authors compared the accuracy of the results with measurements by extracting the point-in-time simulation data nearest to the time of measurement for each of the 540 occupant desks 

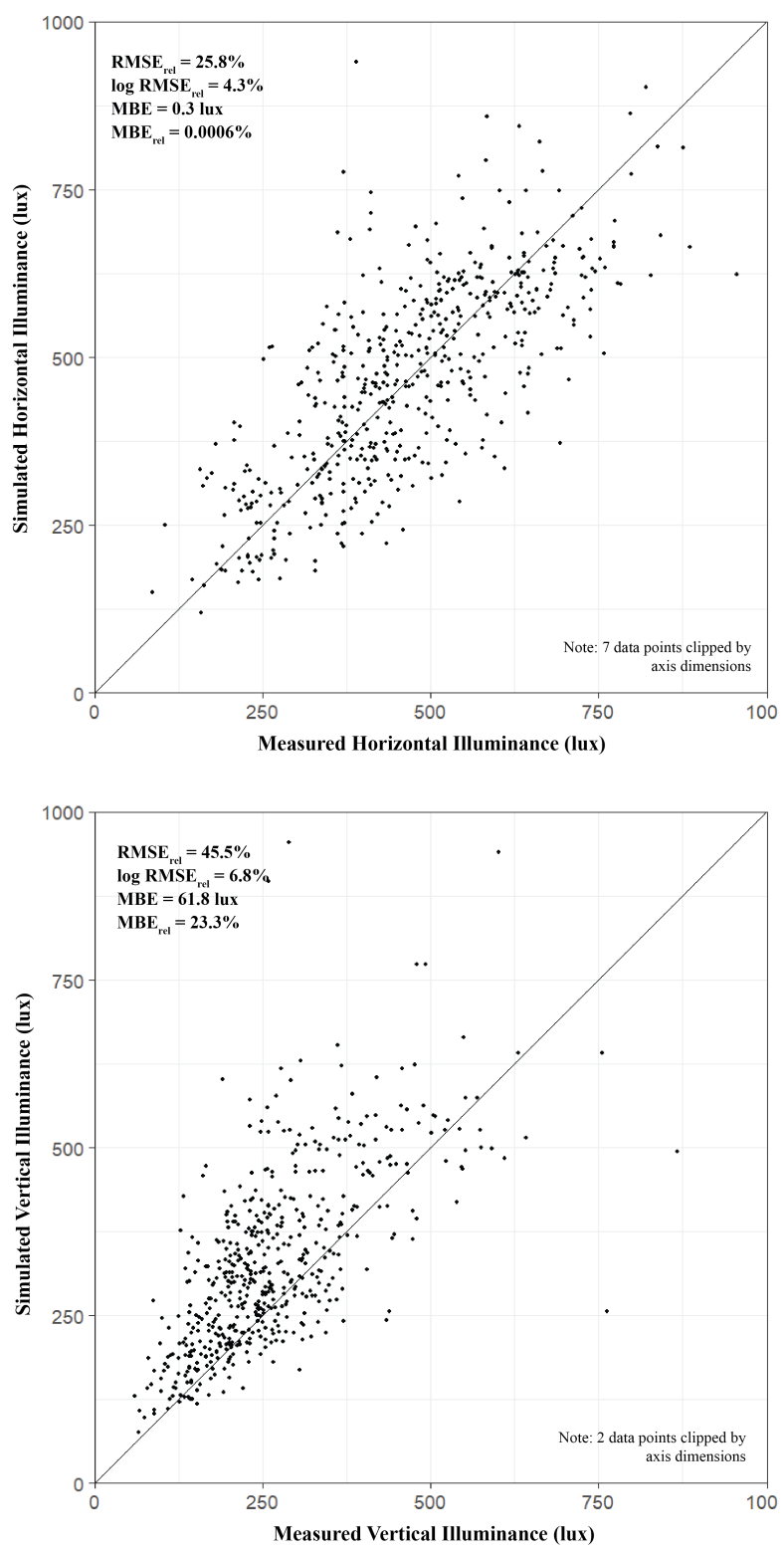

Figure 6: Scatter plots of measured vs simulated horizontal and vertical illuminance.

measured during the 13 month period of this study. $R M S E_{\text {rel }}$ values of $25.8 \%$ and $45.5 \%$ were achieved between sensor measured illuminance and simulated point-in-time illuminances horizontally and vertically as illustrated in Figure 6 . The grey line is a $y=x$ identity line representing the ideal calibration situation. Vertical illuminance deviates from the measured illuminance more than that of horizontal illuminance. Vertical $R M S E_{r e l}$ values are exasperated by the variety of monitor types and configurations measured at various workstations where on/off status, the brightness setting, monitor type, monitor size, and monitor number vary wildly between participants; all of these will have an impact on measured vertical illuminance. Logarithmic differences are known to express perceived lighting differences by the human eye better than actual absolute differences in different lighting situations. (Reinhart and Andersen (2006)) Hence, the authors decided to use $\log R M S E_{\text {rel }}$ as a paired validation measure of the CBDM daylighting models indicating how close calculations come to human perceptual differences in addition to standard linear lighting unit errors. In the base-10 logarithmic visual space, the models had $4.3 \%$ and $6.8 \% \log R M S E_{\text {rel }}$ for horizontal and vertical illuminances respectively. The overall $M B E$ was 0.3 lux $(0.0006 \%)$ and 61.8 lux $(23.3 \%)$ for horizontal and vertical simulated illuminance respectively.
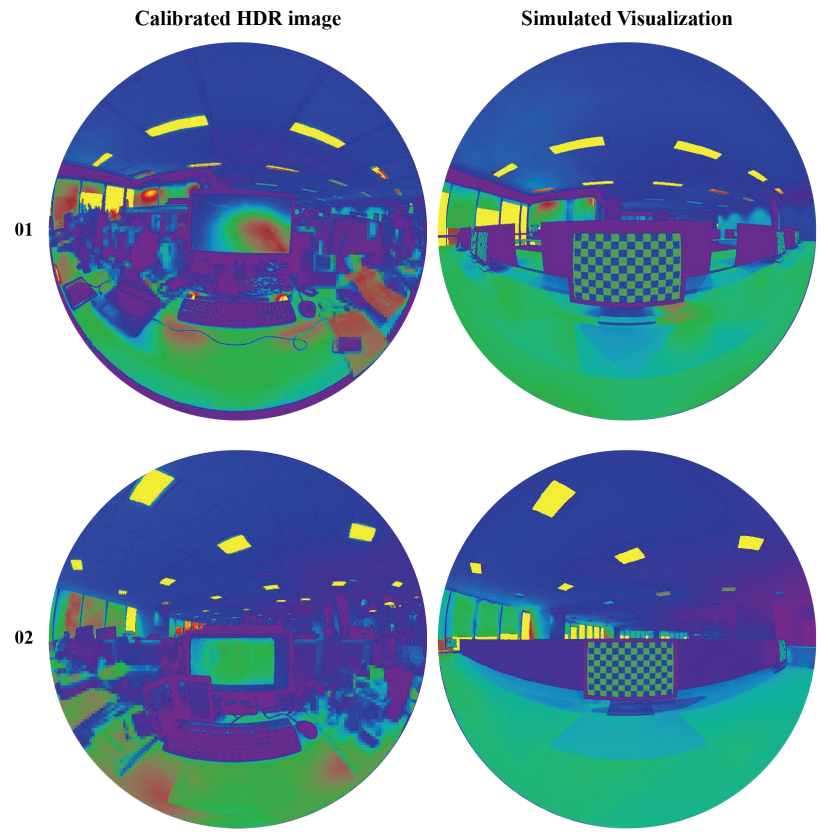

Luminance $\left(\mathbf{c d} / \mathbf{m}^{2}\right)$

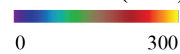

Figure 7: Comparison of calibrated HDR images and simulated visualizations from the same viewpoint.

Figure 7 compares two selected calibrated HDR images to simulated visualizations using false-color luminance images, which are representative of those simulated during the calibration process. Differences specifically in the monitor brightnesses can be observed based on discrete user factors as mentioned as a cause of high vertical errors in the previous paragraph.

\section{Discussion}

The authors believe that sharing their experience with the field measurement and calibration process of the 10 models in this paper would be beneficial to the reader. Although the accuracy of field-calibrated models is not expected to surpass that of those in controlled laboratory setups, it is still a sufficiently reliable method to determine and detect lighting variations in a POE study. Problematic data points with large discrete errors have to be identified and rectified while calibrating the simulation models, as well as correcting for global errors due to electric lighting. In addition, some limitations in practice such as in- 
dividual user differences in monitor screens, items in the workspace, and shade use must be accepted. The authors believe that the validation process presented in this manuscript is important to accurately drive POE results based on calibrated annual lighting simulations by nearly eliminating bias errors and minimizing relative errors. Six participant data points were removed during data analysis due to horizontal and vertical illuminance errors of more than 1,000 lx, which may be attributed to weather data inaccuracies likely due to disparate cloud cover patterns at specific times. These discrepancies are typical and expected of field measurements, unlike precise laboratory measurements that can be controlled to a higher level of accuracy. It is also sometimes difficult to obtain information of actual glazing transmittances for fixed glazing since they cannot be measured easily in the field. Modeling directional and diffusing properties of complex glazing and roller blinds also present challenges where no detailed goniophotometer measurements exist. Where possible, the authors have tried to obtain accurate information from the individual building developers to increase the accuracy of the models. In addition, the location of the weather station may also cause discrepancies in the custom sky models used to simulate the instantaneous lighting data used in calibrations due to global horizontal irradiance being recorded from a different location on the island up to $25 \mathrm{~km}$ away in the case of this study. In the future, portable irradiance data loggers could be utilized at least during the field measurement period.

\section{Conclusion}

The proposed process to build calibrated climatebased models for POE's based on one-time field measurements at each building is validated through comparing measured and simulated illuminance data and the results are sufficiently positive with $\log R M S E_{\text {rel }}$ values of $4.3 \%$ and $6.8 \%$ and $R M S E_{\text {rel }}$ values of $25.8 \%$ and $45.5 \%$ for horizontal and vertical illuminances. While $20 \%$ is often seen as a best-case validation result in the lighting community, the authors suggest that the additional horizontal error observed in this study is acceptable given the complex field conditions and the fact that the errors only make up a small logarithmic perceived logarithmic difference in lighting. As occupied spaces are usually of limited access to researchers, the non-invasive method presented here can allow reliable annual lighting information to be used for POE's through short visits instead of relying on long-term and invasive direct monitoring data using illuminance sensors or HDR photographs. As the proposed workflow does not require constant monitoring and is non-invasive, this could also increase the willingness of participants to engage in lighting POE studies.

The authors find that the proposed workflow of building calibrated models of existing spaces opens up possibilities of assessing long-term quantitative lighting results after a short visit for measurements that can be analyzed in correlation to subjective occupant responses that are collected in the same visit (Jakubiec et al. (2018)). It was found that annual mean illuminance related to the general occupants' satisfaction to access to daylight. The authors acknowledge that the proposed methodology may be more complex than a simpler point-in-time measurement, but building calibrated CBDM daylighting models enables researchers to simulate annual daylighting metrics based on measured annual weather data. At the same time, it is significantly cheaper than long-term monitoring techniques due to fewer demands of manpower and equipment. Predicted lighting results from the design or construction phase of the building may also be analyzed with the post-occupancy results later on, for an additional feedback loop to architects and lighting designers and policymakers for lighting requirements in sustainable building assessment criteria.

\section{References}

Bear, A. R. and R. I. Bell (1992). The csp index: A practical measure of office lighting quality as perceived by the office worker. Lighting Research 86 Technology 24(4), 215-225.

Bellia, L., F. Fragliasso, and E. Stefanizzi (2017). Daylit offices: A comparison between measured parameters assessing light quality and users' opinions. Building and Environment 113, 92-106.

Brembilla, E., J. Mardaljevic, and C. J. Hopfe (2015). Sensitivity analysis studying the impact of reflectance values assigned in climate-based daylight modelling. In Proceedings of Building Simulation.

Choi, J. H., V. Loftness, and A. Aziz (2012). Postoccupancy evaluation of 20 office buildings as basis for future ieq standards and guidelines. Energy and Buildings 46, 167-175.

Technical report IES LM-63-1991, New York (1991). IES Standard File Format for Electronic Transfer of Photometric Data and Related Information.

Dahlan, N. D., P. J. Jones, D. K. Alexander, E. Salleh, and J. Alias (2009). Daylight ratio, luminance, and visual comfort assessments in typical malaysian hostels. Indoor and Built Environment 18(4), 319-335.

Drosou, N., E. Brembilla, J. Mardaljevic, and V. Haines (2016). Reality bites: measuring actual daylighting performance in classrooms. In Proceedings of PLEA. 
Fan, D., B. Painter, and J. Mardaljevic (2009). A data collection method for long-term field studies of visual comfort in real-world daylit office environments. In Proceedings of PLEA, pp. 251-256.

Hirning, M. B., G. L. Isoardi, and I. Cowling (2014). Discomfort glare in open plan green buildings. Energy and Buildings 70, 427-440.

Hirning, M. B., G. L. Isoardi, S. Coyne, V. R. GarciaHansen, and I. Cowling (2013). Post occupancy evaluations relating to discomfort glare: A study of green buildings in brisbane. Building and Environment 59, 349-357.

Hirning, M. B., G. L. Isoardi, and V. R. GarciaHansen (2017). Prediction of discomfort glare from windows under tropical skies. Building and Environment 113, 107-120.

Inanici, M. N. (2006). Evaluation of high dynamic range photography as a luminance data acquisition system. Lighting Research \& Technology 38(2), 123-134.

Jacobs, A. (2012). Radiance cookbook.

Jakubiec, J. A. (2016). Building a database of opaque materials for lighting simulation. In Proceedings of PLEA.

Jakubiec, J. A., G. Quek, and T. Srisamranrungruang (2018). Towards subjectivity in annual climatebased daylight metrics. In Proceedings of Building Simulation.

Jakubiec, J. A. and C. F. Reinhart (2016). A concept for predicting occupants' long-term visual comfort within daylit spaces. Leukos 12(4), 185-202.

Jakubiec, J. A., K. G. Van Den Wymelenberg, M. N. Inanici, and A. Mahic (2016). Accurate measurement of daylit interior scenes using high dynamic range photography. In Proceedings of CIE Lighting Quality and Energy Efficiency.

Jones, N. L. and C. F. Reinhart (2017). Experimental validation of ray tracing as a means of imagebased visual discomfort prediction. Building and Environment 113, 131-150.

Konis, K. (2013). Evaluating daylighting effectiveness and occupant visual comfort in a side-lit open-plan office building in san francisco, california. Building and Environment 59, 662-677.

Konis, K. (2014). Predicting visual comfort in sidelit open-plan core zones: results of a field study pairing high dynamic range images with subjective responses. Energy and Buildings 77, 67-79.
Mangkuto, R. A., K. A. Kurnia, D. N. Azizah, R. T. Atmodipoero, and F. N. Soelami (2017). Determination of discomfort glare criteria for daylit space in indonesia. Solar Energy 149, 151-163.

Mardaljevic, J., E. Brembilla, and N. Drosou (2016). Real-world validation of climate-based daylight metrics: mission impossible? In Proceedings of CIBSE Technical Symposium 2016.

McNeel, R. and Associates (2017). Rhinoceros 3d version 5.0 .

Oseland, N. (2007). British Council for Offices guide to post-occupancy evaluation. British Council for Offices.

Parpairi, K., N. V. Baker, K. A. Steemers, and R. Compagnon (2002). The luminance differences index: a new indicator of user preferences in daylit spaces. Lighting Research 8 Technology 34(1), 5366.

Perez, R., R. Seals, and J. Michalsky (1993). All-weather model for sky luminance distribution-preliminary configuration and validation. Solar energy 50(3), 235-245.

Reindl, D. T., W. A. Beckman, and J. A. Duffie (1990). Diffuse fraction correlations. Solar energy 45(1), 1-7.

Reinhart, C. and A. Fitz (2006). Findings from a survey on the current use of daylight simulations in building design. Energy and Buildings 38(7), 824-835.

Reinhart, C. F. and M. Andersen (2006). Development and validation of a radiance model for a translucent panel. Energy and Buildings 38(7), 890 -904 .

Reinhart, C. F., J. Mardaljevic, and Z. Rogers (2006). Dynamic daylight performance metrics for sustainable building design. Leukos 3(1), 7-31.

Reinhart, C. F., T. Rakha, and D. Weissman (2014). Predicting the daylit area - a comparison of students assessments and simulations at eleven schools of architecture. Leukos 10(4), 193-206.

Reinhart, C. F. and O. Walkenhorst (2001). Validation of dynamic radiance-based daylight simulations for a test office with external blinds. Energy and Buildings 33(7), 683-697.

Ward, G. (1994). The radiance lighting simulation and rendering system. In Proceedings of the 21st Annual Conference on Computer Graphics and Interactive Techniques, pp. 459-472.

Ward, G. (2005). Photosphere, anyhere software. 